\title{
Ley de reestructuración patrimonial. El «procedimiento simplicado» notarial
}

Tomás Sobrevilla ENCIso

El presente ensayo, destinado y dedicado especialmente al Notariado Nacional, se trata de un enfoque, una visión, fundamentalmente jurídica, en este caso procesal, de la parte referida al «Procedimiento Simplificado» de la Nueva Ley Concursal, cuyas características, únicas, son propias del Proceso Concursal Peruano. Constituyen pues, en esa razón, un nuevo Derecho; y, por ello, un derecho en formación, por lo que las opiniones que ahora vertimos han de serlo a beneficio de inventario; con el carácter de meramente provisionales, sujetas, en todo caso, a las resultas de la praxis; serán así, las experiencias de la aplicación de la Ley, las que se encargarán de ratificarlas o rectificarlas.

Por razones de metodología, pero sin apartarnos del marco de la Ley, hemos dividido esta exposición en tres partes: una Primera, relativa a aspectos Generales y Básicos; la Segunda, referida al Procedimiento en sí mismo; y, finalmente, la Tercera, a los Efectos del "Convenio de Reprogramación de Pagos», aspecto este que constituye la verdadera cuestión central o medular-objeto- del «Procedimiento Simplificado».

\section{Aspectos generales básicos}

\section{Concepto y objeto}

Este Procedimiento, que la Ley llama «Simplificado", se trata, en rigor, de un "Convenio de Reprogramación de Pagos", esto es, más propiamente, de una versión remozada y simplificada de los Convenios Extrajudiciales de la antigua Ley Procesal de Quiebras. Se domina Simplificado, no solamente en relación al General mas lato y complejo, y sobre todo de costos mucho más elevados, que fue diseñado, desde la 
Ley anterior, para las grandes empresas, sino, principalmente, respecto al "Acuerdo Global de Refinanciamiento", regulado por el Tit. IX de la Ley, bajo el epígrafe de "Concurso Preventivo", para el cual deben seguirse también, con Excepción de la declaratoria de Insolvencia, los mismos mecanismos procedimentales que norman el Procedimiento General ya mencionado. Es así que, en contraposición a aquellos procedimientos latos, éste, abreviado, o simplificado, tiene por objeto, como explica la Exposición de Motivos, cubrir el universo de las Pequeñas y Medianas Empresas, e incluso las Micro Empresas (si sus costos -notariales- así los permitieran), que se encontrasen en dificultades económicas o financieras iniciales y superables, que, por la simplicidad, brevedad y bajos costos del Procedimiento, podrían acogerse, dentro de este esquema, a los beneficios de su recuperación y/ o reflotamiento. Resulta, pues, así, que el objeto de este «Procedimiento Simplificado» Notarial, es la obtención, por la Empresa, de un "Convenio de Reprogramación de Pagos" con sus acreedores.

Hemos denominado Notarial a este Procedimiento, por cuanto, aun cuando el numeral 92 de la Ley, concede al deudor una alternativa, ya sea para optar por una Notaría o una entidad Delegada, la enumeración taxativa del Art. $131^{\circ}$ no ha conferido tal facultad a dichas entidades (como sí lo hacía en el prepublicación) por lo que, mientras esa omisión no sea expresamente subsanada por ley posterior, $y / 0$ complementaria, el conocimiento-competencia- de esos Procedimientos, sólo será de exclusividad notarial.

\section{Definición de empresa}

El concepto, claro y preciso, que el Notario debe tener de lo que es Empresa es de singular revelancia, por cuanto el Art. $91^{\circ}$ de la Ley sólo otorga el beneficio del Procedimiento Simplificado a las personas Naturales o Jurídicas "consideradas» Empresas, dentro de la definición que de ellas hace el Art. $1^{\circ}$ de dicho Ordenamiento. De hecho, la calificación de Empresa, hecha por la Ley, plantea al Notario una problemática inicial, como básica, para decidir: si admite, o no, a trámite el petitorio. Concretamente; ¿cuándo una persona natural o jurídica «es» una Empresa?; o, zcuándo, mediando qué circunstancias, esa misma persona debe ser "considerada" (equiparada) una Empresa?. La importancia de esta definición radica en que el Notario no podrá admitir a trámite la petición de personas que no reúnan esas calidades, ya que aquellas tienen su propio régimen concursal (título X de la Ley). 
Para tal propósito el Art. $1^{\circ}$ de la Ley define la «Empresa»: $1^{\circ}$.- Como una Organización Económica Autónoma». Vale decir, como un conjunto "orgánico» estructural, debidamente racionalizado, para el desarrollo de sus actividades económicas. Organización autónoma, criterio sancionado por la Doctrina, como la de un ente distinto y diferenciado de la Sociedad o su Titular, que le sirve: de marco legal; 2 ‥ Organización en la que confluyen, como elementos constitutivos de la misma, los factores «capital» y «trabajo»; $3^{\circ}$. Que el objeto, el fin último, de la Empresa es la producción de bienes o la prestación de servicios; y, 4.- Que desde el punto de vista formal de su constitución o existencia, puede adoptar cualesquiera de las modalidades o formalidades, ad-solemnitatem, establecidas por la Ley Mercantil, ó, puede existir de hecho, informalmente, o como aquellas que la Ley las califica con más propiedad como irregulares. Volveremos más adelante sobre este punto.

\section{Esquema del procedimiento}

Caracterizan a este procedimiento su simplicidad y brevedad, que responden al siguiente esquema procesal, el que desarrollaremos mas adelante:

$1^{\circ}$ Presentación del Petitorio.- Cuya Documentación Sustentatoria deberá ser calificada por el Notario.

$2^{\circ}$ Autorización Notarial.- Que habrá de expedir el Notario al solicitante, en caso de encontrar conforme su petitorio, a efectos de que convoque a Junta a sus acreedores.

$3^{\circ}$ Convocatoria a Junta de Acreedores.- Que deberá hacerla el Deudor o Empresa, en forma personal a cada acreedor, y a todos mediante las publicaciones correspondientes.

4ㅇ Instalación de la Junta y Aprobación del Convenio de "Reprogramación de Pagos».- Dos actos, en rigor diferentes, pero que conforme a la Ley, deben realizarse en un solo momento procesal.

Con la Aprobación del Convenio, llega a su término el Procedimiento Simplificado. Sin embargo; pueden presentarse, eventualmente, dos situaciones procesales:

A. La Controversia sobre los créditos que puede surgir entre las fases de la convocatoria a Junta y de instalación de la misma.

B. La Conclusión Anticipada del Procedimiento, que puede darse en 
cualquier momento, antes de que éste, de ordinario, termine con la Aprobación del Convenio.

\section{Rol del notario frente al «procedimiento simplificado»}

El Notario, dentro de la secuencia de este Procedimiento, aparte de las facultades Fedatarias y Comprobatorias propias de su función, establecidas por la Ley de la Materia ( $N$ ㅇ 26002 Art. $2^{\circ}$ ), se halla ahora investido, como consecuencia de la Desjudicialización del Procedimiento, de funciones de naturaleza Procedimental, semejantes a las de los Jueces en el Proceso Común, y que, entre las mas relevantes, podemos destacar:

l⿳ La de Calificación del petitorio y la documentación sustentatoria correspondiente, pudiendo, eventualmente, solicitar información o documentación adicional o complementaria. Incluso, rechazar in-limine, de plano, la petición si la considerase improcedente, o, en su caso transferirla -remitirla- a la Comisión.

$2^{\circ}$ La de Otorgar al peticionario, de encontrar conforme la documentación sustentaroria, la Autorización correspondiente, a fin de que éste haga la respectiva convocatoria a Junta de Acreedores (de aquellos que figuren en la relación adjunta a su petición: Art. 92-3 de la Ley).

$3^{\circ}$ La de Notificación, a petición del solicitante, de la Convocatoria a Junta, a cada uno de los acreedores, en forma personal, mediante comunicación notarial directa, o por intermedio del Auxiliar Notarial así como efectuando la Publicación de los respectivos avisos.

$4^{\circ}$ La de Citación -notificación- a las partes, a comparecer ante él, para los actos conciliatorios correspondientes, en los supuestos de «controversia de los créditos", sea por disconformidad en el monto de los mismos, o, por omisión de alguno de los acreedores en la respectiva relación de obligaciones (Art. $96^{\circ}$ de la Ley).

$5^{\circ}$ La de Declaración -o propiamente resolutiva-, en determinados supuestos (Ej. párrafo $3^{\circ}$ del Art. $94^{\circ}$ ) de Conclusión «anticipada» del Procedimiento.

$6^{\circ}$ De tipo Conciliatorio - en cierto modo arbitral-, cuando interviene para lograr un acuerdo entre las partes en los casos de conciliación de los créditos conforme al Art. $96^{\circ}$ de la Ley. 


\section{Del procedimiento}

Debemos ante todo recalcar; que este "Procedimiento Simplificado» Notarial, es, en su aspecto estrictamente Procedimental, una creación del Derecho Concursal Peruano. Es único. No existe, hasta donde tenemos conocimiento, antecedentes legales al respecto en el ámbito del Derecho Comparado. Es pues, de otra parte, una de las modalidades del criterio de la Desjudicialización (Exposición de Motivos., del Decreto Legislativo № 845, Separata de «El Peruano» páginas 142779 y 142782, II. 4.2), el que si bien ya había sido adoptado, parcialmente, en la Ley anterior (Que limitaba la intervención Judicial exclusivamente al Procedimiento de Quiebra, e incluso a este nivel, en forma muy menguada), ahora resulta de vigencia plena, en términos casi absolutos en la sistemática de la Ley actual. Como consecuencia de ello, se ha hecho exclusión total de la participación Judicial en el Proceso Concursal (ya que la "Quiebra» ha dejado de existir como tal, habiéndose conferido al Juez únicamente el rol de un mero certificador de la extinción de la Empresa y de la incobrabilidad de los créditos impagos) para transferirlos, en todas sus modalidades, a un ente Administrativo: el INDECOPI; correspondiendo, dentro de ese criterio unitario, el conocimiento - competencia del «Procedimiento Simplificado» a los Notarios.

\section{Competencia notarial}

El Legislador; consecuente con el criterio de la Desjudicialización ya expuesto, y, siguiendo la tendencia asumida respecto de los Procedimientos No Contenciosos (Ley 26662), dentro de cuyas características debe, por su naturaleza, inscribirse el «Procedimiento Simplificado"; ha conferido con gran acierto, el conocimiento de este Procedimiento Simplificado, a los Notarios, estableciendo para ello como pautas básicas: $1^{\varrho}$ Una competencia de orden cuantitativa, esto es la del monto de un pasivo que, a la presentación de la petición y durante el curso del procedimiento, no debe superar las 200 UIT (Arts. 91 y 94 , último párrafo); y $2^{\circ}$.- Otra de naturaleza originaria (Art. 103 de la Ley) que hace prevalente la Competencia Notarial, a la que la Ley denomina, impropiamente, "Solicitudes Paralelas», en los supuestos en los que alguno, o algunos, de los acreedores, hubiesen, con posterioridad, solicitado la declaración de insolvencia del deudor ante la Comisión del INDECOPI o la respectiva entidad Delegada. 
1A.- Representación Notarial.- La Ley (Arts. 92, párrafo $2^{\circ}$ y 97 párrafo $2^{\circ}$ ), dispone que el Notario puede ser representado, en determinados actos, por un Representante. En otros términos; se ha creado, sin regularlo expresamente, la figura de la Representación Notarial. Ello, si tenemos en cuenta que el Notario, con arreglo a la Ley de la materia (Art. $3^{\circ}$ de la Ley $\mathrm{N}^{\circ}$ 26002), debe intervenir "personalmente" en los actos propios de su función, lo cual excluye - prohibe- toda y cualquier delegación, puede plantear cierta implicancia. Sin embargo, a nuestro parecer, tal contradicción resulta más aparente que real. En efecto; tratándose el Proceso Concursal de una Ley especial, en observancia de lo dispuesto por su Octava Disposición Complementaria, será este último Ordenamiento el de aplicación preferencial. Siendo así; el Notario, dentro del ámbito del Proceso Concursal, se halla plenamente facultado para designar una persona que lo represente en determinados actos específicamente señalados por la Ley como los consignados por los numerales 92, Párrafo $2^{\circ}$ y 97, Párrafo $2^{\circ}$. Empero, aquella representación, dada la relevancia de los actos, que quien la ostenta debe realizar, habrá de revestir una formalidad adecuada, por lo que será necesario para su designación, la observancia, por lo menos, de las mismas formalidades requeridas para la nominación del Auxiliar o Secretario Notarial en los Procedimientos No Contenciosos.

\section{Presentación del petitorio}

Es un acto formal con el que se da inicio al Procedimiento Concursal Simplificado, con el objeto de que el Deudor pueda legalmente ser autorizado a convocar a Junta a sus acreedores para llevar a cabo un «Convenio de Reprogramación de Pagos» con aquellos. El petitorio, para su admisión a trámite, habrá de hallarse recaudado con la documentación sustentatoria mínima especificada en el Art. 92 de la Ley, y que, entre los más relevantes, deberá contener la relación de obligaciones del deudor y el Proyecto del respectivo convenio (Art. 100). La importancia de estos recaudos radica en el hecho de que los acreedores deben tener conocimiento previo de la situación económica del deudor y, principalmente, de las propuestas (proyecto) de dicho Convenio, para en su caso, reformular o plantear alternativas, cuestiones éstas que deben ser materia de los debates correspondientes de la Junta con intervención del deudor (Art. 98, último párrafo).

De otra parte; debe tenerse en cuenta que, con arreglo al Art. 93 de la Ley, las declaraciones de carácter informativo que contenga el 
petitorio y, en particular, toda información específica contenida en dicho escrito, así como la documentación anexada a esta solicitud, incluso la proporcionada adicionalmente, a requerimiento del Notario, tienen el carácter de declaración jurada, con las consecuencias jurídicas y responsabilidades penales que de esos hechos puedan derivar para el peticionario, e incluso, en su caso, para el Representante Legal de la Empresa (Art. 93 de la Ley y la Exposición de Motivos al respecto).

Presentada, entonces, la solicitud por el Deudor, la labor Notarial habrá de centrarse principalmente en dos aspectos:

$1^{\circ}$ Comprobación -verificación- de la legitimación, calidad o interés legítimo del peticionario; complementando lo expuesto en relación a la definición de la Empresa (Parte I, punto 2), toca ahora, en orden a lo dispuesto en el numeral 91 de la Ley, precisar ¿Cuáles, o quiénes, son aquellas personas naturales o jurídicas que deben ser consideradas Empresas a efectos de acogerse a los beneficios del Procedimiento Simplificado?.

Partiendo de la premisa de que «son» Empresas, las «legalmente» constituidas dentro del marco societario del Ordenamiento Mercantil correspondiente (Ley General de Sociedades, Ley 21621 de las E.I.R.L., etc.), deberán, paralelamente, o por analogía, ser «consideradas» Empresas:

A. Aquellas que al constituirse no hubieran satisfecho a cabalidad las exigencias y formalidades dispuestas por los ordenamientos de la materia; o, que no hubiesen cumplido con la respectiva inscripción registral; o que continuasen en actividad no obstante haber concluido el plazo de duración para su objeto social; pero, en todo caso, personas jurídicas que se hallan, implícitamente autorizadas, obviamente por tratase de cuestiones subsanables (Art. 386 de la Ley General de Sociedades), aunque con ciertas limitaciones, para continuar en vigencia en su condición de irregulares dentro de la definición del numeral 385 de la Ley General de Sociedades.

B. Otra clase de empresas, cuyos titulares deben, por imperativo legal, ser necesariamente personas naturales, y que se hallan al margen del ordenamiento mercantil, razón por la cual se encuentran exentas, para su existencia y constitución, de los requisitos y solemnidades de aquel ordenamiento. Es el caso de las Pequeñas y Medianas Empresas, así como las Micro Empresas, a las que les es suficiente para existir y desarrollar sus actividades mercantiles, una simple inscripción Municipal o cn el respectivo Registro Unificado. Es más, la sola presentación o constancia de la solicitud de inscripción, en dichos Registros, resulta habilitándolas para su funcionamiento y operatividad. Obviamente se trata, 
en estos casos, de Empresas o de personas naturales que deben ser «consideradas», para los efectos de la Ley Concursal, Empresas.

Concretando lo expuesto; podrán acogerse a los beneficios del Procedimiento Simplificado (siempre que su pasivo no supere las 200 UIT) $1^{\circ}$.- Todas las Empresas que se hallan formal y legalmente constituidas dentro del marco societario de la Ley General de Sociedades u otras especiales como las E.I.R.L. (Ley 21621); $2^{\circ}$.- Deberán ser «consideradas» Empresas; las personas jurídicas societarias calificadas por el ordenamiento mercantil como irregulares dentro de la definición del Art. 385 de aquel ordenamiento y, $3^{\circ}$.- También habrán de ser «consideradas» Empresas, las Personas Naturales, bajo las modalidades de Pequeñas y Medianas Empresas, incluso la Micro Empresas, siempre y cuando se hallen registradas en un Padrón Municipal (o que recauden su petitorio con la respectiva constancia de haber solicitado su inscripción: Ley $\mathrm{N}^{\mathrm{o}}$ 23189), o, en su caso, inscritos en el respectivo Registro Unificado (Decreto Supremo 118-90-P.C.M., de 14-09-90).

En consecuencia; el Notario no podrá admitir a trámite peticiones de Personas Naturales que no reúnan los requisitos consignados, aunque ejercieran actividades comerciales, mercantiles o industriales. Tampoco podrá admitir las solicitudes de Personas Jurídicas que al realizar actividades no lucrativas no pueden ser «consideradas» Empresas, como las reguladas por el Código Civil (Asociaciones, Fundaciones, etc.), por tener, además, todas aquellas personas, como anotamos, un Régimen Concursal propio normado por el Título X de la Ley.

$2^{\mathrm{o}}$ Verificación de los requisitos exigidos por el Art. 92 de la Ley. Especialmente, respecto de la Relación de Obligaciones (créditos) presentada por el peticionario (apartado 3 ), toda vez que, la suma total (no mayor de las 200 UIT) de los respectivos montos (por los conceptos de capital, interés y gastos), habrá de determinar la competencia del Notario para conocer de estos Procedimientos.

De otro lado; en caso de que el Notario considerarse insuficiente la documentación anexada al petitorio, está facultado para solicitar del peticionario la información adicional o complementaria que juzgue conveniente (Art. 92 último párrafo).

Finalmente; cabe acotar, que si bien es cierto que la Ley (Art. 94 párrafo $3^{\circ}$ ) prescribe que si durante el curso del procedimiento, el Notario comprueba que los pasivos del deudor superan las 200 UIT (límite de su competencia), deberá remitir todo lo actuado a la Comisión para los efectos legales correspondientes, no dice nada, en cambio (tampoco la Exposición de Motivos), respecto del supuesto de que el Notario advirtiera, ab-initio, al tiempo de la calificación del petitorio y los recaudos 
acompañados, la total improcedencia de la petición. Por nuestra parte, somos de opinión de que el Notario podría, alternativamente: denegar in-limine la solicitud, a efectos de que el deudor ejercite su derecho directamente ante la Comisión o que, aplicando por extensión el criterio del Art. 94 párrafo $3^{\circ}$ de la Ley, remita el petitorio con todos sus recaudos, a la Comisión, para que ésta proceda conforme a lo señalado en el supuesto anterior (Procedimiento de Declaratoria de Insolvencia).

\section{Autorización notarial}

Satisfechos, a criterio del Notario, los requisitos exigidos por los Arts. 91 y 92 de la Ley, para la procedencia del petitorio, este funcionario, previa certificación en acta de ese hecho, procederá a otorgar al solicitante la Autorización correspondiente, a efectos de que el deudor pueda convocar a Junta a sus acreedores. Esta autorización habrá de tener la formalidad de una simple declaración Notarial (no la de una Resolución) expedida a mérito, o como resultado, de haberse satisfecho a cabalidad los requisitos -presupuestos-legales de los citados dispositivos.

\section{Convocatoria a junta de acreedores}

A estarse al texto del numeral 94 de la Ley, expedida la autorización correspondiente, la convocatoria a Junta de Acreedores deberá correr por cuenta, cargo y responsabilidad, del Deudor Empresa. Empero; ello no obsta, a nuestro entender, que tal convocatoria pueda hacerse, si el peticionario así lo prefiere, mediante el Notario que expidió la autorización.

Esta convocatoria, lo será para dos fechas consecutivas con dos días hábiles de por medio (aplicación sustitutoria, en lo pertinente, del Art. 21) con indicación exacta del lugar, día y hora, para cada una de ellas, como lo precisa la Exposición de Motivos (párrafo relativo a la publicidad), y debe revestir dos formalidades copulativas: una principal -la más importante-, que debe hacerse en forma personal (bajo cargo) a cada uno de los acreedores, obviamente adjuntando copias, por lo menos, de la relación de obligaciones así como del Proyecto del "Convenio de Reprogramación de Pagos»; y, otra de carácter complementaria, mediante publicación de un aviso, por una sola vez; en el diario oficial «El Peruano», tratándose de Lima y Callao; y, en Provincias, en el periódico 
encargado de los avisos judiciales. Publicaciones en las que, además deberá indicarse; que la documentación sustentatoria correspondiente, y, principalmente, el Proyecto de Convenio se hallan a disposición de los acreedores en la respectiva Notaría; y el plazo legal (Art. 96 párrafo $l^{\circ}$ ), dentro del cual, los acreedores tienen el derecho de observar o impugnar, en lo que a cada cual concierna, la relación de las obligaciones crediticias presentada por el peticionario.

De otra parte; teniéndose en cuenta que el plazo (de cuando menos de 30 días hábiles posteriores) para la realización de la Junta, a estarse a lo dispuesto en el Art. 95, para la realización de la Junta, deberá computarse: en un caso, a partir de la publicación para la primera convocatoria; $y$, en otro supuesto, desde la notificación personal a los acreedores, que de ser muchos, y no haber podido, por esa razón, hacerse simultáneamente (el mismo día) dichas notificaciones, ese plazo deberá empezar a correr, obviamente, desde la última notificación. Esta dualidad normativa (publicaciones y notificaciones), ante el riesgo que ella conlleva, y, a fin de evitar obstáculos y tropiezos procesales sobrevinientes, aconseja que el señalamiento para las convocatorias se haga de manera suficientemente holgada.

\section{5. «Controversia» respecto de los créditos}

Puede ocurrir que, luego de efectuada la Convocatoria, alguno o algunos de los acreedores formulen observaciones de carácter controversial, planteando ello, con arreglo al párrafo $1^{\circ}$ del numeral 96 de la Ley, dos situaciones: $1^{\circ}$.- La disconformidad entre el crédito, o créditos, del impugnante respecto al monto o cuantía asignados o declarados por el Deudor en la relación correspondiente (Art. 92-3 de la Ley): 0,2 .- Que el impugnante, invocando su calidad de acreedor, alegue no haber sido considerado -omitido- en dicha relación. Cuestiones éstas que deben ser definidas resueltas mediante un breve procedimiento, el que, confirme se desprende del texto del párrafo $2{ }^{\circ}$ del art. 96, deberá responder al siguiente esquema:

$1^{\circ}$ Los Acreedores, disconformes u omitidos, deberán hacer valer su derecho ante el Notario, mediante un escrito, adjuntando la documentación sustentatoria correspondiente, dentro de los 15 días hábiles anteriores al de la fecha señalada para la primera Junta (Art. 96 párrafo $1^{\circ}$ ). Este plazo es de caducidad. Por tanto, producirá efectos extintivos plenos, esto es que no podrá, en adelante, formularse a nivel Notarial, re- 
clamación ni articulación alguna al respecto. Sin embargo ello no puede obstar, en nuestra opinión, a que tanto el acreedor que considerase que su acreencia fue consignada como menguada o diminitua, o, aquel otro cuyo crédito hubiera sido excluido -omitido- de la relación de obligaciones, puedan ejercitar judicialmente, las acciones declarativas correspondientes, ya que, tampoco, aparte de que no podrían ser privados de esos derechos por una cuestión meramente formal, el INDECOPI -Comisión-, a nuestro entender, carecería de competencia para pronunciarse en abstracto sobre estas cuestiones (en este caso, de naturaleza estrictamente jurisdiccional), de no mediar un Procedimiento Administrativo, vía declaratoria de insolvencia del deudor o Empresa.

$2^{\circ}$ El Notario deberá citar - notificar- a ambas partes a comparecer ante él, a efectos de la respectiva conciliación; acepción que, en este caso, debe ser entendida; primero; en relación a una diferencia de montos crediticios, como la de cotejo o comprobación documentaria de las afirmaciones de las partes, a fin de establecer la exactitud de los créditos, ó, en el supuesto de omisión de un crédito, como la de comprobación instrumental, respecto de la existencia, procedencia, legitimidad y cuantía de la acreencia omitida; y, en segundo lugar; la conciliación, esta vez, en su sentido procesal: como el acto de acuerdo o consenso a que arribaren las partes sobre la cuestión planteada (controversia como la califica la Ley), para cuyo propósito el Notario puede desempeñar un rol de tipo Arbitral: de verdadero conciliador.

En caso de no ser posible la conciliación instrumental -documentaria- en cuanto al monto (exactitud) crediticio, o no arribarse a un acuerdo de partes a este respecto, o en relación a la inclusión de la acreencia omitida, el Notario deberá remitir, reza la Ley, la «documentación pertinente» a la Comisión, para que ésta, con arreglo al procedimiento correspondiente, resuelva la cuestión -conflicto de interesesplanteada.

Por otro lado; ni la Ley ni la Exposición de Motivos, dicen nada, respecto al hecho, de qué efectos produciría la remisión de lo actuado, a la Comisión, en lo tocante a la realización de la Junta "ya convocada», entre tanto aquella cuestión, de tipo incidental, sea resuelta por la referida institución. Piensan algunos (expositores del INDECOPI en la Conferencia en el Colegio de Notarios: 29 de Octubre de 1996) que tal articulación produce efectos suspensivos del procedimiento. Es más, que el Notario, en tales supuestos, estaría autorizado a suspender o diferir la realización de la Junta postergándola para la oportunidad correspondiente (Resuelta que fuera por la Comisión la cuestión controversial sobre 
los créditos). Por nuestra parte; creemos, primeramente; que el Notario, a quien la Ley ni siquiera ha facultado a convocar a Junta de Acreedores por propia iniciativa, sino solamente a «autorizar», tal convocatoria, al propio deudor, el único llamado a efectuarla (salvo que se la encomiende o delegue al Notario), mal podría estar facultado el Notario para suspender la convocatoria o disponer la postergación de la misma; y, segundo; que, teniéndose en cuenta que una suspensión prolongada, sobre todo como consecuencia de un eventual uso de recursos impugnatorios, podría ocasionar un colapso o falencia total, irreversible, de la Empresa (ya aquejada de una crisis inicial que, precisamente, trata de superar), y que la finalidad y objeto, perseguidos por la Ley, es el de su recuperación o reflotamiento, cuestiones que no podrían esperar más dilaciones, pensamos, que, tratándose, procesalmente, de una simple cuestión incidental (que puede correr por cuerda separada), nada obstaría para que el procedimiento siga adelante con la instalación de la Junta, en la que podría intervenir el impugnante con el porcentaje que arroje su acreencia en la parte no impugnada, quedando la diferencia como acreencia contingente. Y, en cuanto al acreedor omitido, su crédito podría, también, ser considerado como contingente; vale decir, en ambos casos, como condicionados a lo que en definitiva resuelva el INDECOPI (aplicación extensiva del último párrafo del Art. 23 de la Ley).

\section{Instalación de la Junta}

Bajo este epígrafe debemos comprender dos aspectos relativos a la Junta: una primera, la de constitución (con el «quórum» de Ley) e instalación (Acto formal) de dicha Junta, como ente organizado de los que tradicionalmente era, y aún lo es a nivel de Derecho Comparado, de la "masa» de acreedores; y, luego, en esa calidad de órgano representativo de todos los acreedores, hallarse investida de facultades de decisión, en este caso, sobre la aprobación, o no, del convenio propuesto por el deudor. Es así como, reunidos los Acreedores, en el lugar día y hora señalados, el Notario, a efectos de la Instalación de la Junta, deberá, previamente, certificar, en cada caso (1a. y 2 a. convocatorias) el quórum correspondiente, con arreglo a las pautas del Art. 26, párrafo $1^{0}$ de la Ley, esto es tratándose en este caso de sólo dos fechas, las mayorías serán del $66.6 \%$ para la primera, y más del $50 \%$ para la segunda. Igualmente, instalada la Junta, el Notario o su Representante, habrán también de certificar las mayorías requeridas para el Acuerdo de Aprobación 
del Convenio. Es obvio que aún cuando la ley omita decirlo, al tiempo de dicha instalación la Junta deberá elegir un Presidente y un Vicepresidente (tal como aparece en los «modelos» editados por el propio INDECOPI) para los efectos de la conducción -orden- de los debates, así como para las decisiones -acuerdos- que, eventualmente (supuesto de suspensión: Art. 98, párrafo $3^{\circ}$ ), adopte la Junta, toda vez que las funciones -rol- del Notario en estos actos se hallarán limitadas a las fedatarias y/o comprobatorias correspondientes.

\section{Aprobación del convenio}

El acto de aprobación del Convenio no es tan simple, como piensan algunos (expositores del INDECOPI en el «Seminario de Reestructuración Patrimonial»: 20 de noviembre de 1996 en la Universidad Católica) que deba limitarse a una mera votación, en el sentido de que, inmediatamente -de plano-, de instalada la Junta, debe aceptarse, o no, el Proyecto presentado por el Deudor. El Convenio es pues un acto de concertación, de consenso, por lo que dicha Propuesta debe ser puesta, aunque fuere sólo formalmente, a debate. Es más; pueden, al respecto, haberse formulado observaciones o modificatorias, e incluso planteado contrapropuestas por alguno, de los acreedores: cuestiones todas estas que, igualmente, deben ser sometiads a debate, y que, excepcionalmente, pueden dar lugar a una postergación del acuerdo de la Junta (Art. 98 párrafo $3^{\circ}$ ). Es así como, luego de instalada la Junta (Art. 98); al término de los debates; en los que podrá intervenir oralmente el Deudor o Empresa (Art. 98 último párrafo), a efectos de exponer las causas que motivaron su crisis y sustentar el Convenio propuesto, y los acreedores, respecto de las modificatorias o contrapuestas que hubiesen formulado; el Presidente de la Junta, someterá a votación el referido "Convenio de Reprogramación de Pagos" y, de ser el caso, también las modificatorias o propuestas que hubiesen sido hechas por los asistentes. Por su parte, el Notario o su Representante, intervendrán en dichos actos en su calidad únicamente de Fedatarios (certificando el quórum, las respectivas mayorías, etc.). Aprobado el convenio en los términos acordados por las partes, mediante las mayorías calificadas establecidas por la Ley para ese acto (Art. 98 párrafo $2^{\circ}$ ), el acta correspondiente deberá ser suscrita por el Presidente de la Junta, un acreedor designado por los acreedores asistentes (Documento Modelo del INDECOPI) y el Notario. 


\section{Finalización del procedimiento}

El «Procedimiento Simplificado» seguido ante Notario, finaliza con la Aprobación del "Convenio de Reprogramación de Pagos", en los términos acordados por las Partes. Por la misma razón, concluirá, también definitivamente, toda intervención notarial, sin más solemnidad que el acto final y formal del levantamiento del acta correspondiente (y el archivamiento del expedientillo), toda vez que no requerirá, para su validez, que tal convenio sea materia de Escrituración Pública. El acta Notarial es su único instrumento constitutivo, en este caso ad-solemnitatem, para que surta plenos efectos jurídicos, y, desde luego, comience a ejecutarse. Debemos recalcar que, finalizado-concluido-el Procedimiento Notarial, en adelante, cualesquiera cuestión divergente o controvertida, derivada del convenio (ejecución de lo pactado, incumplimiento parcial o total, etc.) que surja entre el deudor y los acreedores, no podrá demandar la intervención Notarial para ser ventilada o tramitada a manera de continuación o reapertura del «Procedimiento Simplificado». Los efectos extintivos de la aprobación son totales. Plenos.

\section{A. Inscripción registral}

Empero lo expuesto en el párrafo precedente. Si es cierto que el «Convenio de Reprogramación de Pagos» suscrito por el deudor y sus acreedores, surte plenos efectos jurídicos entre los estipulantes, para su validez y eficacia -erga omnes-frente a terceros, requiere de una formalidad: su inscripción registral, la que a tenor del Art. 99 párrafo $1^{\circ}$ de la Ley, y la Exposición de Motivos que lo informa, habrá de efectuarse, tratándose de personas jurídicas, en el Registro Mercantil, y en el Personal, en el caso de personas naturales; inscripciones, para las cuales, será suficiente la presentación de una copia certificada Notarial del respectivo documento.

En lo tocante a quién corresponde solicitar o efectuar las inscripciones, habrá de tenerse en cuenta, a falta de norma legal expresa al respecto, el precepto remisorio del último párrafo del numeral 99 , en este caso

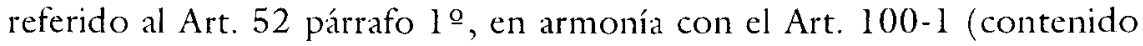
del Convenio), de cuyo tenor debemos entender que, constituyendo el nombramiento $\mathrm{y} / \mathrm{o}$ ratificación del Administrador una cuestión inherente a los convenios de "Reprogramación de Pagos", será pues a este a quien toque llevar a cabo tales inscripciones. Sin embargo, nada puede obstar para que quienes tengan un legítimo interés, como el deudor, o 
alguno de los acreedores, puedan hacerlo de mediar para ello urgencias o necesidades que la ameriten. Por otro lado; aquella inscripción registral habrá de regir, por su naturaleza cautelar, todo el tiempo, -plazo- de ejecución del convenio, por lo que, una vez cumplido este a cabalidad (pago de todas las obligaciones), al haber caducado por carecer de objeto, habrá de ser levantada. Para la cancelación de dicha inscripción, deberán seguirse los mismos procedimientos, en lo pertinente y aplicable, dispuestos por la Ley para la conclusión del Proceso de Reestructuración Empresarial (Arts. 57-2 y 58, en función de lo prescrito por el numeral 104).

\section{Conclusión anticipada del procedimiento}

De ordinario, o regularmente, el «Procedimiento Simplificado» Notarial debe terminar, como vimos, con la aprobación del Convenio. Sin embargo, puede suceder, excepcionalmente, que se presenten factores o circunstancias procesales que interrumpan su curso o extingan el Proceso antes de que este concluya de modo regular, a semejanza de lo que ocurre en el Proceso Común, (Art. 474 del C.P.C.). Es así, entonces, que en el Proceso Concursal, en orden a lo prescrito por la Cuarta Disposición Complementaria de la Ley, habrán de ser también de observancia los mismos principios generales que informan la institución de la Conclusión Anticipada del Proceso. Ello, dentro del «Procedimiento Simplificado» Notarial, puede ocurrir:

$1^{Q}$ Si durante la secuencia del Procedimiento, conforme al Art. 94 último párrafo de la Ley, el monto del pasivo superase las 200 UIT (por ejemplo, en los supuestos de "controversia respecto de los créditos» Art. 96 , en la que la conciliación de los mismos arrojara un monto muy superior al que figurase en la relación de obligaciones -Art. 93-3 de la Ley- presentada por el deudor, cuantía que hiciera superar el pasivo de las 200 UIT; o que esa demasía resultara como consecuencia de la inclusión de un crédito - acreedor- que, inicialmente, no había sido considerado -omitido- en dicha relación), en cuyo caso el Procedimiento Notarial concluirá para dar inicio, ante la Comisión (a la que se remitirá lo actuado), al más lato y general, de la Declaratoria de Insolvencia, obviamente, como solicitado por el propio deudor con arreglo a las pautas del Art. 5 de la Ley.

$2^{\circ}$ Si el Notario comprueba, o toma conocimiento, en cualquier momento, de la existencia de una solicitud de declaratoria de insolvencia, 
presentada con anterioridad a la petición del Procedimiento Simplificado, es obvio que, acorde al principio de la competencia originaria o "preventiva", contenida en el numeral 103 (bajo el epígrafe impropio de solicitudes paralelas y una redacción imprecisa), al prevalecer la competencia de la Comisión respecto de la Notarial, esta última debe cesar de pleno derecho. En estos supuestos el Notario deberá proceder a extender el acta correspondiente, mediante la cual dará -declararápor concluido el procedimiento, disponiendo a la vez el archivo del expedientillo.

$3^{\circ}$ Si la Junta de Acreedores (se entiende ya instalada) no llegare a adoptar acuerdo alguno. Este es el supuesto del numeral 101 de la Ley, que autoriza al Notario a declarar la conclusión del procedimiento. La Exposición de Motivos acota, en relación a este punto, que el Notario «se encuentra en obligación» de efectuar una declaración, en razón de que, siendo el objeto del procedimiento la "celeridad y eficacia» del mismo, los "debates y discusiones" al "interior de la Junta", no resultan «ideales» para tales propósitos. Por nuestra parte creemos que la referida Exposición de Motivos ha rebasado la ley, cayendo en excesos. En efecto, el rol del Notario, durante la realización de los debates, debe limitarse únicamente a la de Fedatario. La dirección de los mismos corresponde exclusivamente al Presidente de la Junta o quien los acreedores al tiempo de su instalación hubieran designado. Es pues a dicha persona a quien toca, mediando tales circunstancias (sobre todo en los supuestos de haberse, excepcionalmente y por única vez, postergado el acuerdo: Art. 98 párrafo $3^{\circ}$ ), dar por agotados los debates y someter a votación la aprobación del convenio en los términos que resultaron finalmente planteados. Recién, entonces, habrá de intervenir el Notario; primero; para certificar el resultado de la votación; y, luego, si es que ella no arrojara las mayorías exigidas por el precepto remisorio del numeral 98 , párrafo $2^{\circ}$ de la Ley (Art. 36) para la aprobación del convenio, declarar, en vista de que la Junta no llegó a adoptar Acuerdo alguno al respecto, la conclusión del Procedimiento.

La ley no ha previsto; tampoco la Exposición de Motivos dice nada al respecto; la falta de Instalación de la Junta, hecho que puede ocurrir, tanto por inasistencia de los acreedores a la convocatoria, en las fechas señaladas al efecto, o que, ocurriendo algunos, o varios de ellos, la Junta no pueda instalarse por falta de quórum o de la mayoría requerida para ello. Se trata pues, en rigor, de situaciones similares o análogas en sus efectos, a la del párrafo precedente; esta vez no pudo llevarse a cabo ningún acuerdo por ausencia de un presupuesto: la falta -inexistenciade una Junta de Acreedores. En estos casos resulta obvio que el Nota- 
rio deberá preceder del mismo ue en el anterior: certificar el hecho (inasistencia, en su caso, de los acreedores, o falta de quórum) y luego declarar la conclusión del Procedimiento.

Cabe advertir, que esta modalidad de Conclusión Anticipada del Procedimiento, no puede impedir que los acreedores puedan ejercitar sus derechos ante la Comisión solicitando, si fuera el caso, la declaratoria de insolvencia del deudor, o que éste, de motu - proprio, si sus pérdidas patrimoniales hubiesen llegado a superar las dos terceras partes del total, haga tal petición (Art. 5 de la Ley).

$4^{\circ}$ Si el Deudor se desistiera de su petición (Procedimiento); aún cuando la ley no ha previsto esta situación procesal, nada obsta para que, en observancia de lo prescrito por la Cuarta Disposición Complementaria, in-fine de la ley (aplicación supletoria del C.P.C.), pueda el deudor, en este caso antes de la realización de la Junta, retirar de hecho la solicitud presentada al Notario, o desistirse «formalmente»-por escrito- con arreglo, en lo pertinente, a los Arts. 340 y siguientes del Ordenamiento Procesal. Ante esta situación, el Notario, previa certificación de ese hecho en acta, deberá proceder a la devolución, al deudor, del petitorio con sus respectivos anexos (documentos), quedando así extinguido dicho procedimiento.

\section{Efectos del convenio}

\section{Validez y eficacia del convenio}

En observancia del precepto remisorio del numeral 99, último párrafo, de la Ley, que hace de vigencia el Art. 48 del mismo Ordenamiento, aprobado y suscrito el convenio, éste surtirá plenos efectos frente a todos los acreedores, aún contra aquellos que no se hubieran apersonado al procedimiento o hubieran votado en contrario, con la sola excepción de aquellos que no hubiesen sido considerados -omitidos- en la relación de obligaciones (Art. 92-3) presentada por el deudor, a quienes no podrá oponerse dicho convenio. De igual manera; la inscripción registral del mismo, surtirá, desde que se haga, efectos-erga omnes- respecto de terceros.

\section{Efectos suspensivos procesales y sustantivos}

Las imprecisiones de los párrafos $\mathrm{I}^{\circ}$ y último del Art. 99, al remitirse a 
los numerales 16 y 17 del mismo Ordenamiento, parecieran envolver un contrasentido. En efecto; si la suspensión de la exigibilidad de todas las obligaciones (Art. 16) del deudor, así como de las medidas de ejecución y de determinadas medidas cautelares (Art. 17) han de surtir plenos efectos con posterioridad-inmediatamente y como consecuencia- a la aprobación del convenio, ello no tendría razón de ser; sería ocioso, puesto que celebrado, -suscrito e inscrito-, aquel pacto, es obvio que ya, dentro de sus respectivas estipulaciones, se decidió, por acuerdo de partes, todo lo relativo al aspecto central y medular de la «Reprogramación de Pagos»: el pago total de las obligaciones y el régimen de los respectivos intereses. De la misma manera debió haber ocurrido en lo tocante a los procesos de ejecución y determinadas medidas cautelares (Art. 17), por lo que, una suspensión pos convenio, carecería totalmente de objeto, por lo menos resultaría muy tardía, más aún si se tiene en cuenta que desde la presentación de la solicitud hasta la realización de la Junta, concretamente hasta la aprobación del convenio, por más de que se trate de un trámite breve y simple (autorización, publicaciones, citaciones, plazo para la realización de la Junta, eventual controversia sobre los créditos, etc.), habrá de transcurrir, en la práctica, un tiempo apreciable (cuando menos de dos a tres meses, o aún mucho más), suficiente para hacer efectivas las acciones efectivas, ejecuciones forzosas, medidas cautelares, etc., las que, tratándose de una Empresa ya afectada de crisis económica o financiera que la llevaron -obligaron- a convocar a sus acreedores podrían de no decretarse la inmediata suspensión de tales medidas, determinar su colapso o falencia total e irreversible, que es precisamente lo que la Ley no quiere.

Frente a la situación planteada; creemos que las medidas suspensivas dispuestas por la Ley deben surtir sus efectos plenos desde la fecha de presentación del petitorio ante el Notario vale decir, con anterioridad a la aprobación del Convenio, aunque, obviamente condicionadas a la materialización -suscripción e inscripción-de tal acto. Sustentamos nuestra opinión en lo siguiente:

lo En que la declaración de insolvencia, en el Proceso lato o General, al dar paso, de pleno derecho, a la Convocatoria a Junta de Acreedores, establece un "Estado concursal». De la misma manera, la autorización Notarial (acto formal) a efectos también de una Convocatoria a Junta de Acreedores, a nivel de «Procedimiento Simplificado» (que precisamente es simplificado en relación a aquel), genera una Situación Concursal (concurrencia de una pluralidad -totalidad- de acreedores frente a un deudor común). Por consecuencia; a dicha situación 
concursal le serán aplicables los mismos principios vigentes para la primera (eadem ratio, idem jus). Concretamente; habrán de observarse en el presente caso, los mismos criterios que informan los numerales $16 \mathrm{y}$ 17 de la Ley a los que se remite el último párrafo del numeral 99 del mismo Ordenamiento.

$2^{\circ}$ Que dentro del propósito -objeto- perseguido por la Ley: lograr, por un lado, la recuperación de la Empresa (en este caso su salida de una crisis económica-financiera inicial o transitoria), y por otro, el cumplimiento de la totalidad de sus obligaciones; surge pues la necesidad imperiosa, como con claridad y explicitez precisa, a este respecto, la Exposición de Motivos: «de proteger la masa patrimonial del deudor con el fin de ponerla a disposición de -todos- los acreedores...»; objetivo que solamente puede ser posible dictando normas tendientes a impedir, detener o paralizar, acciones o pretensiones (exigibilidad de obligaciones, procesos de ejecución, etc.) de alguno o algunos de los acreedores, incluso de terceros, que tiendan a afectar, menguar o disminuir el patrimonio empresarial, creando así una situación de espera (stand by), de alivio de la Empresa, hasta en tanto en cuanto se arribe, vía convenio de «Reprogramación de Pagos», a una solución definitiva de la crisis que la aqueja.

$3^{0}$ Finalmente; como es de verse de la Exposición de Motivos, esta vez en relación a la «obligación» de los Notarios de declarar la conclusión - anticipada - del procedimiento, en la que se precisa, que aquella obligación tiene, entre otros objetos, el de no mantener «un estado de suspensión de la exigibilidad de las obligaciones por tiempo indefinido", de lo cual resulta, obviamente, que tales efectos suspensivos ya venían operando aún mucho antes de la instalación de la Junta (Desde la presentación del petitorio o la autorización Notarial correspondiente).

Dentro del criterio expuesto, de protección del patrimonio empresarial, como reza el epígrafe -sumilla- del Art. 17 de la Ley, y precisa, como acotamos, la Exposición de Motivos, como la «...necesidad de proteger la masa patrimonial del deudor...» a efectos de su recuperación o salida de una crisis inicial o transitoria, así como, por otra parte, asegurar a los acreedores el pago total de sus créditos, las medidas a adoptarse habrán de comprender dos aspectos o situaciones a saber: $1^{\circ}$.Unas; de naturaleza Procedimental, y, por ello, de carácter cautelar, provisional; de efectos inmediatos, que operan a la sola presentación del petitorio y son anteriores y previos al acuerdo de Junta; su objeto es, ya sea el de impedir el inicio de toda acción ejecutiva, o toda pretensión cautelar previa (embargos preventivos), contra el patrimonio del deudor, 
o el de suspender los procesos de ejecución (venta y/o remate) así como las medidas cautelares que persigan la ejecución (embargos definitivos) del patrimonio empresarial. Estas medidas provisionales se hallan, por su condición de tales, sujetas a las resultas de las aprobación del convenio, que, de materializarse - suscribirse e inscribirse pasarán a constituirse en permanentes - definitivas - hasta el total cumplimiento - ejecución de lo pactado (pago de todas las obligaciones); y; 2 ‥ Otras medidas, de naturaleza esencialmente Sustantiva, las que si bien, en un primer momento, resultarán condicionantes de determinados aspectos relativos al contenido del convenio (intereses), surtirán recién, efectos plenos, luego de aprobado aquel pacto; efectos que habrán de ser permanentes o si se quiere definitivos, de vigencia hasta el total cumplimiento de lo estipulado (pago de todos los créditos).

Como corolario de lo expuesto, y en orden a lo dispuesto, en lo pertinente, en los numerales 16 y 17, por remisión del Art. 99 último párrafo de la Ley, tendremos:

1 - En cuanto a las medidas suspensivas de naturaleza Procedimental y de carácter provisional; de vigencia a partir de la presentación del petitorio y sujetas a las resultas de la aprobación o no del Convenio:

A. La suspensión de la exigibilidad de "todas» las obligaciones. Acepción ésta ( «exigibilidad»), empleada por la Ley, que habrá de entenderse, en este caso, en un sentido procesal; vale decir, como la del derecho o facultad del acreedor, de ejercitar -iniciar- una acción -demanda- judicial, o de análoga naturaleza (Arbitral, Coactiva, etc.), contra el deudor, con el objeto de hacer efectiva -ejecutar- una obligación crediticia pura (exigible); o como el derecho o potestad del titular del crédito de solicitar una medida cautelar previa (embargos preventivos), sobre bienes del deudor o Empresa. Suspensiones que deben comprender "todas" las obligaciones del deudor, sin excepción alguna (principales y accesoria). Es más, no sólo las vencidas a la fecha de la «presentación» del petitorio párrafo $2^{\circ}$ del Art. 99 , sino también a aquellas que fueren venciendo durante la secuencia del procedimiento hasta aprobación del convenio.

B. La suspensión, en este caso, con arreglo, en lo pertinente, al Art. 17 de la Ley (penúltimo párrafo), de todos los Procesos Judiciales y de análoga naturaleza (Arbitrales, Coactivos, etc.), que se hallasen en curso, y que tengan por objeto la ejecución de bienes que conformen el patrimonio de la Empresa (ejecución de sentencias -remates- de garantías, etc.).

C. La suspensión, de acuerdo también al dispositivo acotado, de to- 
das las medidas cautelares, ya sea que estuviesen únicamente decretadas, 0 , de aquellas, que ya materializadas (definitivas), tengan por finalidad la ejecución forzada -remate- de bienes de la Empresa.

Por otra parte; cabe acotar que para la efectivización de las medidas suspensivas materia de los párrafos precedentes, bastará, por aplicación

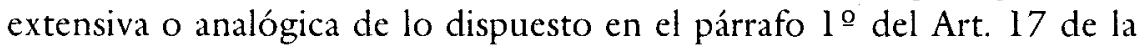
Ley, que el deudor o en su caso, el Representante legal de la Empresa, se apersonen a los respectivos procedimientos, adjuntando la certificación o constancia notarial de la presentación del petitorio o de la correspondiente autorización para la convocatoria a Junta de Acreedores, a mérito de cuyas instrumentales, los Jueces habrán de decretar las referidas suspensiones.

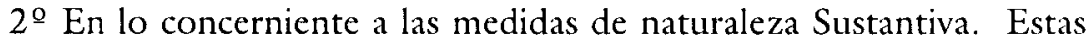
medidas, relativas a la suspensión de la «exigibilidad» de las obligaciones, acepción entendida, esta vez, en su sentido de sustantivo inciden acorde al Art. 16 párrafo $1^{\circ}$ de la Ley, en el aspecto tocante al régimen de los compensatorios (Art. 1242, párrafo $1^{\circ}$, del C.C.) en el sentido de que deberá comprenderse en el convenio la tasa originariamente estipulada y, en defecto de pacto, la legal que corresponda; y, segundo; la improcedencia -prohibición de la inclusión en el pacto, de «Reprogramación de pagos» de los intereses moratorios (Arts. 1242 párrafo $2^{\circ}$, y 1243 del C.C.) así como la capacitación de los intereses (Arts. 1249 y 1250 del C.C.), aún cuando aquellas modalidades hubiesen sido expresa y originariamente convenidas. Por consecuencia; las medidas dispuestas por el citado párrafo $!^{\circ}$ del numeral 99 de la Ley, habrán de materializarse:

A. Condicionando y/o limitando la aprobación -celebración-del convenio, en lo concerniente al régimen de intereses, el que deberá sujetarse a las pautas señaladas por la Ley (Art. 16 párrafo $1^{\circ}$ ) y dentro de los términos precisados sobre este punto por la Exposición de Motivos (Comentario del Art. 99).

B. Una vez aprobado -suscrito e inscrito- el convenio, dicho régimen surtirá efectos permanentes, aunque referidos a la fecha de la presentación del petitorio, hasta el total cumplimiento (pago de todas las obligaciones) de dicho pacto.

Cabe finalmente, acotar, respecto de los efectos suspensivos del convenio que cumplido dicho pacto (pago de la totalidad de los créditos), por efectos extintivos del pago (Art. 1225 del C.C.), habrán también de quedar fenecidos, de pleno derecho, todos los procesos cualesquiera fuere su naturaleza (judiciales, arbitrales, etc.), incluido en ellos los 
cautelares correspondientes, salvo los supuestos en los que el convenio resulte inoponible a los accionantes. La extinción -caducidad-de aquellos procedimientos deberá ser declarada por los respectivos Jueces a petición del deudor, o de un tercero legitimado, recaudada, ya sea con la certificación que al efecto deba expedir el Administrador, de haberse cumplido con el pago de la totalidad de las obligaciones materia del convenio o, en su defecto, con la certificación Registral del levantamiento o cancelación de la inscripción de dicho convenio.

\section{Inoponibilidad del convenio}

Conforme a lo dispuesto en el párrafo $3^{9}$ del numeral 99 de la Ley, el principio general de la validez y eficacia del convenio frente a todos los acreedores (Art. 48 , párrafo $1^{\circ}$, por remisión del último párrafo, del

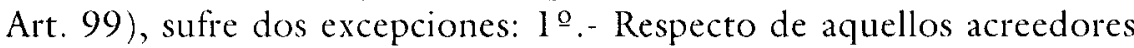
que no fueron considerados -omitidos- en la relación de obligaciones presentada por el deudor (Art. 92-3); y, 2‥ En lo tocante a "terceros» garantes -otorgantes de garantías reales o personales- "que así lo hubieran previsto al momento de constituirse como tales» (Art. 99, párrafo $3^{\circ}$, in fine).

En cuanto a lo primero. Es obvio que el convenio no podría ser opuesto a los acreedores que fueron excluidos -omitidos- de la relación presentada por el deudor, o que, habiéndola contradicho oportunamente (Controversia sobre los créditos: Art. 96), hubieran sido posteriormente calificados como tales por la Comisión (INDECOPI), a menos que, durante el acuerdo aprobatorio, se hubiese considerado -previstotales créditos como contingentes (Art. 23), en cuyo supuesto cobrarán vigencia en el respectivo cronograma de pagos. Igual criterio, aunque la Ley no lo mencione, deberá observarse, por extensión o analogía, respecto de los acreedores que habiendo impugnado el monto de sus créditos, por ser mayores a los consignados en la respectiva relación, hubieran, también obtenido con posterioridad, una calificación favorable de la Comisión, limitándose, en este caso, las pretensiones de los acreedores, solamente por la diferencia, a menos que esa suma hubiera sido considerada como acreencia contingente.

Por consecuencia; no siendo oponible (inaplicable como dice la Ley) el convenio a esta clase de acreedores, estos tendrán expeditos sus derechos para iniciar las acciones judiciales, o de análoga naturaleza (arbittrales, coactivas, etc.) correspondientes o, en su caso, continuar 
con las que se hallaban en curso, y que habían quedado suspendidas hasta la aprobación -celebración- del convenio (Art. 99 párrafo $2^{\circ}$ ).

En lo tocante a lo segundo. Ante la falta de claridad de la norma, y el silencio de la Exposición de Motivos al respecto, debemos entender que el párrafo $3^{\circ}$ in-fine, del numcral 99 , es ratificatorio, por vía de remisión, del criterio que informa el párrafo $3^{\circ}$ del Art. 16, el que comprende, a su vez, dos situaciones: una, referida a la facultad de los acreedores de ejecutar a terceros garantes; $y$, otra, relativa al derecho de éstos a subrogarse al acreedor pagado. De ello habrá de resultar:

$1^{\circ}$ En lo concerniente a la responsabilidad de los garantes en relación a los acreedores. La extensión y alcances de tal responsabilidad se halla sujeta, sobre todo en las personales (Art. 1873 del C.C.), a los límites de lo expresamente estipulado ("que así lo hubieran previsto..." reza la Ley: Art. 99, párrafo $3^{\circ}$ in fine) en el respectivo pacto de garantía. Consecuentemente; si los garantes asumieron las obligaciones del deudor no sólo respecto de la obligación principal y los intereses compensatorios, sino también por los moratorios y la capitalización correspondiente, la acción persecutoria de los acreedores -potestativa y ejercitable durante la vigencia del convenio-por estos últimos conceptos, será procedente (Art. 16, último párrafo); en esa virtud, los garantes no podrán oponer el convenio a los acreedores ejecutantes, alegando que mediante dicho pacto se hubo liberado a aquellos del pago exigibilidad-de las obligaciones relativas a los intereses moratorios y la respectiva capitalización, y que, en esa razón, no estarían obligados, por vía de subrogación, a pagar más de lo que el deudor garantido debe oblar en virtud del convenio. De otro lado, deberá tenerse en cuenta que, dentro del criterio de la protección del patrimonio de la Empresa en crisis -superable-, aquel beneficio de la «inexigibilidad» es «personal», de aquellas cuya naturaleza es intuito personae, y que, en esa virtud, no podría hacerse extensiva a terceros que sólo tienen, en este caso, la calidad de garantes. Es más; cn el supuesto de que éstos se hubieran constituido con el carácter de solidarios (caso de la fianza) tampoco, por efectos de la solidaridad, acorde a los principios que informan los numerales 1186,1195 y $1883-2$ del C.C., pueden formular oposición alguna contra los acreedores accionantes.

$2^{\circ}$ En lo concerniente a la Subrogación de los Garantes. Si es cierto que ella, acorde al Art. 16 párrafo $3^{\circ}$ in-fine de la Ley, opera de pleno derecho, lo que en realidad importa ( $y$ es en este aspecto en el que más se deja sentir la deficiencia normativa, párrafo $3^{0}$ del Art. 99, y la ausencia de la Exposición de Motivos), es saber cuál medida, la amplitud, de 
ese derecho subrogatorio de los garantes, habida cuenta de que estos pagaron la integridad de la obligación, incluidos los intereses moratorios y aquellos capitalizados (devengados hasta la fecha de la presentación del petitorio), mientras que el deudor-obligado principal sólo habría de pagar, a los subrogantes, una suma diminuta, como consecuencia de haber quedado excluidos del convenio aquellos extremos originariamente pactados. A ello debemos agregar, que, en observancia de la suspensión de todas las obligaciones, dispuesta por el párrafo $2^{\circ}$ del numeral 99 de la Ley, los garantes se hallarían impedidos de ejercitar, contra el deudor garantido, cualquier acción repetitoria más allá de la suma consignada en el respectivo cronograma de pagos en favor de los acreedores subrogados, en cuyos derechos se sustituyeron los garantes.

Frente a la situación planteada; debemos tener en cuenta; en primer término; que, al producir la subrogación efectos del pleno derecho (Art. 16 párrafo $3^{\circ}$, in-fine de la Ley y 1260 del C.C.), el garante, que pagó la totalidad de la obligación devengada, hasta la fecha de la presentación del petitorio, tiene el derecho de repetir por el íntegro de lo pagado; en segundo lugar; como consecuencia de lo anterior; el garante no puede ser privado de ese derecho, porque, lo contrario, importaría sancionar un enriquecimiento indebido que la Ley no puede amparar; en tercer lugar; que el principio de protección del patrimonio del deudor, en beneficio tanto de la Empresa (recuperación y/o reflotamiento) como de los acreedores (pago de la totalidad de sus créditos), bajo la fórmula de una «Reprogramación de Pagos» es, en relación a los garantes, una cuestión de terceros (res inter alios), que, en esa razón, no puede perjudicarles; $y$, finalmente; con arreglo al párrafo $3^{\circ}$ del numeral 99, entendido en su más lato sentido, se trata tan solamente de una suspensión de la exigibilidad de las obligaciones, que, en todo caso, debe regir únicamente durante la vigencia -plazo- de ejecución del convenio; no más allá.

Como consecuencia de lo expuesto; en nuestra opinión; si bien los garantes no podrían ejercitar contra el deudor, durante el plazo de vigencia del convenio, ninguna acción repetitoria por la diferencia resultante (intereses moratorios y los capitalizados), y, de hacerlo, puede aquel oponerles dicho pacto, en cambio, cumplido - ejecutado- el convenio, al haber caducado los efectos suspensivos de éste, los garantes tendrían expeditos sus derechos para accionar contra el deudor por ese remanente, en cuyo caso, éste no podría oponer el convenio a los ejecutantes. 


\section{Inejecución del convenio}

Durante la ejecución del Convenio pueden presentarse dos situaciones: una, de incumplimiento parcial en relación a un acreedor en particular, el que no pudo ser pagado en el modo y forma establecidos en el respectivo cronograma de pagos; $y$, otra, referida a la imposibilidad sobreviniente - fracaso- de continuación de la ejecución del convenio de «Reprogramación de Pagos», considerado esta vez en su integridad estructural. Situación, esta última, irreversible, materializada en una verdadera cesación de pagos que no puede brindar otra alternativa que la liquidación de la Empresa.

En cuanto al Primer Supuesto.- El párrafo $4^{\circ}$, segunda parte, del numeral 99 de la Ley, autoriza al "acreedor afectado" a hacer valer su derecho en la «vía correspondiente». Esta terminología genérica, de «vía correspondiente», utilizada por la Ley, debemos en principio, y desde el punto de vista procesal, entenderla como la facultad conferida al acreedor impago, para el ejercicio de las acciones judiciales comunes correspondientes (procesos de Conocimiento, Abreviado, de ejecución, etc.). Sin embargo; en el supuesto de que, en aplicación, por vía de remisión, del Art. 17, los procesos de ejecución, así como determinados procedimientos cautelares (ya iniciados o en curso), en sus respectivos niveles procedimentales (judiciales, arbitrales, coactivos, etc.), hubiesen quedado suspendidos; en observancia de lo dispuesto por el Art. 59 de la Ley, tales medidas suspensivas, habrán de ser levantadas, a petición del acreedor afectado con el incumplimiento, a fin de que éste pueda continuar con la ejecución y obtener, por ese medio, el pago de su acreencia la que, en este caso, debe entenderse por el monto total de su crédito, aun cuando en el cronograma de pagos se hubiera establecido una modalidad de pago por cuotas o en forma periódica. Correlativamente; es obvio que el deudor puede obtener el corte del procedimiento (incoado o reiniciado) mediante la respectiva consignación (mas costas y costos), quedando de ese modo regularizado, en este supuesto, la ejecución del convenio.

En lo Concerniente a la «Imposibilidad» de Continuación de la Ejecución del Convenio.- La ley Concursal no ha previsto esta situación, como si lo hiciera en una circunstancia análoga, respecto de la Reestructuración Patrimonial -Empresarial-, mediante su numeral 56, para el supuesto de que no sea «posible» la continuación de dicho proceso. Empero, la ausencia de una regulación explícita no obsta, a nuestro parecer, que esa deficiencia sea salvada a mérito del precepto remisorio del numeral 104. En efecto; debemos tener en cuenta, para nuestro propósi- 
to, la similitud, y diríase hasta identidad existente entre el proceso lato y genérico de la "Reestructuración Patrimonial» y el «Simplificado» (que precisamente lo es en relación a aquel) de «Reprogramación de Pagos», toda vez que ambos en sus aspectos medulares: el Plan de Reestructuración y el «contenido» del Convenio de Reprogramación, numerales 47 y 100, respectivamente, en sus apartados 1 al 7, son los mismos; guardan identidad entre si. En ambos; la ejecución del «Plan» y la del «Convenio", se hallan, o deben hallarse a cargo de un Administrador, cualesquiera fuere la modalidad del régimen de administración acordado o convenido al respecto. Es mas; ambas vías, la general o lata, y la simplificada, o breve, pérsiguen los mismos objetivos: la recuperación y/o reflotamiento de la Empresa en dificultades económico-financieras y el pago de la totalidad de sus créditos a los acreedores. Por consecuencia; deberán, dentro del Procedimiento Simplificado, ante una situación de imposibilidad sobreviniente -fracaso- de la continuación de la ejecución del convenio, de aplicarse los mismos criterios que rigen para los supuestos del proceso de Reestructuración Patrimonial. Concretamente; en observancia, en lo pertinente, de lo dispuesto en el Art. 56 de la Ley, deberá corresponder al Administrador, ya sea por propia iniciativa o a petición de los acreedores que representen más del $30 \%$ de los créditos, convocar a Junta de Acreedores, a efectos de que dicha Junta decida (Destino de la Empresa) sobre la Disolución y Liquidación de la Empresa, en cuyo caso habrán de observarse, por extensión o analogía y, en lo pertinente, las pautas procedimentales señaladas por la ley para tales supuestos.

Complementando lo expuesto en el párrafo precedente; ante el silencio o deficiencia de la Ley en este punto pueden caber, además, en nuestra opinión, otras alternativas, tales como; en relación a los Acreedores; solicitar de la Comisión, si para ello se satisfacen los requisitos correspondientes (Art. 4), la declaratoria de insolvencia del deudor para, por esa vía, decidir en Junta (Art. 35) la disolución y liquidación de la Empresa; respecto del Deudor, si también éste cumple con los requisitos que le corresponden (Art. 5), solicitar su propia declaratoria de insolvencia; y finalmente de no poder satisfacerse las exigencias -presupuestos- de la Ley Concursal (Art. 4 y 5 ) para obtener la declaratoria de insolvencia, habrá de irse a la liquidación dentro del marco de la Ley General de Sociedades. Concretamente; en base a la causal del Art. 359-2 de la referida Ley, observándose para ello los procedimientos correspondientes, en armonía con el numeral 363 párrafo $1^{\circ}$ (convocatoria a Junta a petición de los accionistas: párrafo $1^{\circ}$ ), o, en su caso, con arreglo al párrafo $3^{\circ}$ del mismo dispositivo (judicialmente). 